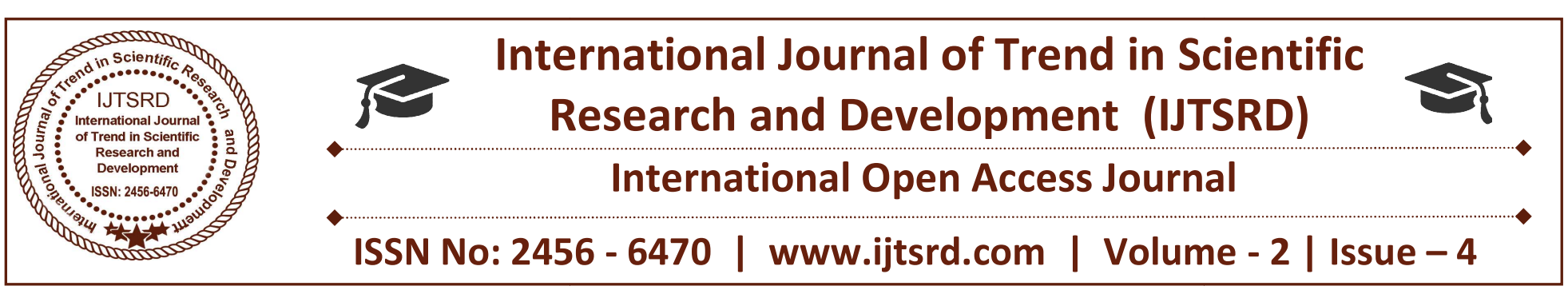

\title{
The Use of Historical Controls in Post-Test only Non-Equivalent Control Group
}

\author{
Lillykutty M. J' ${ }^{1}$, Dr. Rebecca Samson ${ }^{2}$ \\ ${ }^{1} \mathrm{Ph}$.D Scholar, INC National Consortium for Ph.D in Nursing, New Delhi, India \\ ${ }^{2}$ Dean, College of Nursing, Pondicherry Institute of Medical Sciences Kalapet, Puducherry, India
}

\section{ABSTRACT}

Implementation of historical controls and concurrent controls in post-test only non-equivalent control design was a novel undertaking for a research study titled "Effect of structured nursing care rounds on satisfaction with nursing care among adult medical surgical patients". The comparison groups involved in this study were three: historical control, concurrent control and experiential groups. Further, this nonequivalent control group posttest-only design study utilized a posttest as well. According to the independent sample t-test analysis, the mean score in the experimental group, for overall satisfaction with nursing care was significantly higher (105.74 \pm 8.4 , $\mathrm{t}=37.03, \quad \mathrm{p}<0.001)$ than in the control group (73.41 \pm 12.57$)$ with a mean difference of 32.33, $(\mathrm{t}=37.03, \mathrm{p}<0.001)$. With regard to the mean percentage of overall satisfaction, the experimental group marked $84.6 \%$. This study also compared the historical and the post-test data of the experimental group on patient satisfaction with nursing care. The statistical computations performed using the difference between two independent means procedure found a considerable mean difference of $(28.75$, $\mathrm{t}=35.33, \mathrm{p}<0.001)$ in this as well. As a well-designed study that showed superiority of SNCR to routine care provides strong evidence of the effect of the new intervention and the addition of historical data supported the conclusion of effectiveness.

Keywords: structured nursing care rounds, historical control, concurrent control, experimental group.

\section{INTRODUCTION}

The strength of any research work is the valid inferences drawn from the data. Valid inferences endow new knowledge, leading to internal and external validity that research results stand for. It is the degree to which a manipulated variable accounts for changes in a dependent variable. A variety of research designs can be used to evaluate the external and internal validity of new interventions. Each differs in its sufficiency in relation to effects and universal application. The robust research designs are true-experimental designs. They embrace control groups to which participants have been at random allocated.

Quasi-experimental designs stand for a fine adjustment when randomization is not possible. This is a two group design, when one group is introduced to a new treatment/ intervention, at the same time, the other group serves as a control/comparison group. Although the control group is not exposed to the new treatment/intervention, both groups are in the same way tested as well. The data from both groups are compared in order to estimate the effects of new treatment/intervention. The poorest of experimental designs which jeopardize internal validity is preexperimental design. These lack adequate control groups to support the claim that an experimental treatment/condition makes a difference.

Quasi-experimental non-equivalent groups design: A non-equivalent groups design is a between-subjects design in which participants are not randomly distributed to experimental and control conditions. In a between-subjects experiment, when participants are randomly assigned to conditions, the resulting groups are likely to be quite similar or equivalent. Whereas when participants are not randomly assigned to 
conditions, the resulting groups are likely to be dissimilar in some ways. For this reason, researchers consider them to be non-equivalent.

\section{Post test only non-equivalent groups design:}

Quasi-experimental non-equivalent control groups post-test only design is a fine negotiation when randomization and pre-test are not likely. In this design, participants in one group are exposed to a treatment/intervention; another non-equivalent group is not exposed to the treatment/intervention, and then the groups are compared. When the participants are not randomly assigned to two groups, there could be differences between them. For this reason, research with a post-test only non-equivalent groups design takes steps to ensure that their groups are the same as possible

\section{Experimental vs. Control groups:}

In general, a trial is divided into two groups; one is an experimental group and the other is a control group. An experimental group is the subjects in an experiment that be given the independent variable being tested. The experiment (test variable) is exactly the same for all members. A scientific control group is an indispensable part of a number of research designs as well. The control group is a baseline to compare and assess the effect of a new intervention. For this reason, a control group (comparison group) that receives no test variable makes sure that the experiment actually works. Further, the researcher can ensure that no other variables but the independent variable caused the statistical difference in an experiment

\section{Types of control groups in Medical/Nursing experiments}

As slated by Stephanie (2017), control groups in medical experiments are the following types:

A. Placebo concurrent control: one group is given the treatment, the other a placebo

B. Does-comparison concurrent control: two different doses are administered to each group

C. No treatment concurrent control: new treatment is given to one group; the other group receives nothing.

D. Active treatment concurrent control: one group is given the treatment; the other group is given an existing therapy that is known to be effective

\section{Historical control:}

Only one physical group exists experimentally (experimental group). The control group is compiled from historical data.

\section{Concurrent vs. Historical controls Concurrent control:}

Concurrent control is an active group of subjects who are in routine treatment condition, usually provided regularly. When the concurrent control receives the routine/standard intervention, the treatment/intervention group is exposed to the experimental intervention. Concurrent controls are recruited simultaneously (concurrently) with the treatment subjects from the same source of population for the same period of study and measured at the same time with experimental group.

\section{Historical control:}

A historical control is wherever an old data is used to evaluate against the new data from new trials. According to a line from Segen's Medical Dictionary (2012), historical control is the earlier data from patients with similar pathological conditions. Extraordinarily, the historical data is considered for comparison with subjects being treated or assessed concurrently. Naturally, the sources of data might come from older clinical trials, medical chart, and a prospective study. Historical control is generally employed in researches where there are ethical reasons not to use a control group or pre-test. If historical data is used instead of a concurrent control, every person in the trial is introduced to experimental condition, meaning to say, the comparison is with historical data.

In line with Glasziou et al. (2007), a good number of clinical trials compared morbidity or mortality in current patients treated with a new treatment with that in apparently similar, past patients (historical controls) who had either received another treatment, or no treatment. In keeping with the view of Baker \& Lideman (2001), a historical control must be carefully chosen so that they are reasonably compatible with concurrent groups. They must be past patients who had either received routine care/no new intervention. This approach can result in accurate point estimates, increased power and decreased Type II error rates. As good as ever, comparison of current patients with 'historical control' yield trustworthy results and provide convincing evidences on the effect of new treatment/intervention. 
Pursuant to the view of Marc K Walton (2012), historical control is subjects treated in the past with the standard form of care whose outcomes are used to compare with patients receiving the new intervention. Data collected at two separate times (past and present); from different groups of patients is a historically controlled study. The comparison is between 'two different times'. The sources of historical data are from (1) prospective natural history study and medical chart data from a clinical care and (2) control group from a prior randomized investigational study.

Similarly, the outlook of Edmund A. Gehan, (1984) was that all clinical trials, both randomized and not randomized, must be explained in a historical framework. The studies, therefore, must be interpreted in the light of previous and concurrent data in the same area of clinical research. No single clinical trial is an island in itself; instead slowly evolving transition from historical environment into the concurrent stage of a research work. Any clinical trial intended to experiment a new treatment, and at the same time no pre-test is given to experimental subjects, then the comparator to the treated group is not a concurrent separate group of patients but the past group. Historical data support comparative conclusion that the study-end difference is caused by manipulated variable.

Factors that support historical controlled trials is endpoint statistical difference, less time between when historical data collection and the new intervention, accurate and reliable measurement, less time for changes in concomitant care, use of similar data collection process and instruments and equal size of the sample. Historical control studies compare statistically the outcomes in a group of patients treated with new intervention to a different group of patients who did not receive the same in the past. Any study that compares data, not only from two concurrent groups (i.e. uses data collected at two separate times) is a historically controlled research.

The advantage of a historically controlled study is a valid basis for reaching conclusions about interventional effect. Under certain circumstances, which are not usual, like absence of pre-test or concurrent control, it provides a sound basis for conclusions. The factors that strengthen historically controlled comparison are small time period between collection of the historical data and conduct of the treatment trial, broad based historical data sheet and large effect of new drug treatment/intervention. Statistical comparison is the procedure that leads to a conclusion. The view of Jigar R Desai et.al (2013) is that the lack of efficiency, coupled with power concerns about post-test only design, has renewed focus on the use of historical controls and concurrent controls to optimize strength of study.

\section{Historical control in the present study:}

An illustrative example of historical control is the research on novel intervention of structured nursing care rounds involving adult medical surgical patients. The clinical trial was divided into three groups; one was an experimental group and the others were a concurrent control group and a historical control group. The historical control data with regard to selected patient satisfaction with nursing care was compared with concurrent control and experimental data.

The research framework was a non equivalent control group post-test only research design. Due to challenges with extraneous variables, a post-test only design was appropriated to study the effect of structured nursing care rounds on patient satisfaction with nursing care. The study was completed with 300 historical controls, 300 concurrent controls and 300 experimental, yielding 900 samples of adult medical surgical patients.

The nature of the intervention was such that the subjects were not pre-tested; compared the patient satisfaction with nursing care after they have been introduced with 2 different mode of nursing care rounds (post-test only). The data from the historical control and concurrent control was used to compare the data from experimental group so that only the independent variable (SNCR) can be the cause of the changes in patient satisfaction with nursing care. For the purpose of the study, researcher selected two groups of wards at the same hospital, where the structure and nursing care style were almost similar. The researcher allowed the staff nurses to get familiar with the SNCR for an extended period of eight weeks. After the 8th week, the researcher collected the data from patients and compared the data using carefully chosen concurrent control and historical data. This study relied on comparing satisfaction with nursing care in current patients in both groups; the one group introduced to SNCR and the other introduced to 
routine care and also historical control of the experimental group. Taking these steps increased the internal validity of the study because it was able to eliminate some of the confounding variables. The other confounding variables that the researcher was not able to control were addressed by comparing historical control and concurrent control data with experimental data.

\section{Background of the study:}

Customary rounds on patients and regular presence at their bedside are noteworthy features of the nursing profession. An early, evidence-based framework that stretched as far back as the 1860s was the 'regular rounds' by Florence Nightingale on hospitalized patients.1 The growing body of literature related to nursing care, reveals that the Nightingale style has expanded dramatically, awakened echoes in nursing circles and resulted in its resurgence across clinical nursing practice at the global level ${ }^{2}$

\section{Need and significance:}

A well-informed interest for nursing rounds (hourly and bi-hourly) and its interconnected positive effects was reported in 2006; Meade, Bursell and Ketelsen published a hallmark study investigating the effects of nurse rounding on patient satisfaction and safety. The focal point of evidence for this prime scientific study in nursing literature was on the measures of call bell usage, falls, pressure ulcer incidence and patient satisfaction. This six-week nationwide research using a quasi-experimental non-equivalent group design revealed a statistically significant increase in patient satisfaction scores $(12 \%, \mathrm{p}=0.001), 52 \%$ reduction in patient falls, 37\% reduction in light use $(p=0.007)$, $14 \%$ decline in skin breakdowns and $20 \%$ reduction in the distance walked each day by the nursing staff. ${ }^{15}$

\section{Patient satisfaction with nursing care:}

Nursing care is an important aspect of patient satisfaction because nurses are the frontline persons that patients most likely are to meet with, spend the highest amount of time with and rely upon for recovery. It is stated that the most important factor influencing patients' satisfaction with hospital care is their satisfaction with the nursing care. ${ }^{43}$

\section{Statement of the problem:}

Effect of Structured Nursing Care Rounds (SNCR) on satisfaction with nursing care among adult medical surgical patients at a tertiary care hospital, Kerala.

\section{Objectives of the study:}

The major objectives of this study were: Assess the effect of SNCR on satisfaction with nursing care Find the statistical association between satisfaction with nursing care and selected demographic variables of patients

\section{Research hypotheses:}

The stated research hypotheses are also expressed as null hypotheses.

\section{H1.1:}

The mean score for satisfaction with nursing care will be higher in adult medical-surgical patient sample exposed to SNCR than in the control groups exposed to routine care at 0.05 level of significance. H01.1: There is no difference between the experimental and control groups of adult medical-surgical patients with regard to their mean score on satisfaction with nursing care at 0.05 level of significance.

\section{H2:}

There will be an association between patient satisfaction with nursing care and selected demographic variables of the patient sample at 0.05 level of significance. H02: There will be no statistical association between the patient satisfaction with nursing care and the selected demographic variables of patient sample at 0.05 level of significance.

\section{Operational definitions:}

Structured Nursing Care Rounds (SNCR): SNCR refers to regular nurse-patient interaction involving nine caring behaviors. This involves hourly visit of the nursing personnel to each patient between $8.00 \mathrm{am}$ to $9.00 \mathrm{pm}$ and bi-hourly between $10.00 \mathrm{pm}$ to 7.00 a.m. The intervention requires the nursing personnel to physically enter patients' room at stipulated hours to assess their condition and to effectively respond to their needs. This bedside visits prompt the nursing personnel to be proactive in identifying the real needs of the patients rather than being reactive to the routine stimuli like call bells/caregiver access to nursing station and doing the fixed nursing tasks. The nine specific behaviors (9Ps) emphasized in SNCR are the following: (i) Person-centered care: Introduce self and get to know the patient by name and condition. (ii) Plan and brief: Focus on hourly bedside visit; and brief this plan to patients in order to put them at ease. Deal with: (iii) Pain, (iv) Position, (v) Phlebitis and intravenous infiltration, ensure (vi) Proximity of needed personal items. (vii) Perform faithfully the 
fundamental care as well as other scheduled tasks. Pay attention to: (viii) Patient education including discharge plan. Ensure (ix) Presence of nursing personnel to each patient every hour from 8.00 am to $9.00 \mathrm{pm}$, thereafter, every two hours or as and when required.

\section{Patient satisfaction with nursing care:}

Refers to the self-report of patients in adult medical and surgical wards regarding their satisfaction with the information and instructions provided by nurses, their caring behaviours, discharge plan and procedures, overall hospital and nursing services during their hospital stay, and the intention to recommend the hospital to family and friends, as measured by modified 'Patient Satisfaction with Nursing Care Quality Questionnaire' and graded on a Likert scale as 'excellent' 'very good' 'good' 'fair' or 'poor.' Data from the Likert scale are reduced to three categories by combining 'excellent', 'very good' and 'good' responses into good satisfaction, 'fair' responses into moderate satisfaction and 'poor' responses as poor satisfaction.

\section{Adult medical surgical patients:}

In this study they are the adult patients who are diagnosed with medical or surgical pathology in the branch of general medicine, general surgery, neurology and neuro-surgery, cardiology and cardiothoracic surgery, nephrology and urology, orthopaedics and gastroenterology, and are admitted in the selected medical or surgical wards during the data collection period. They consist of four independent groups of patients; three groups in the control condition (routine care) and one group in experimental condition (SNCR). The data is independent of those in the other, provided by different, unrelated, unpaired patients who make up the sample for data collection.

Statistical comparison that leads to a conclusion

Table 1: Distribution of demographic variables in experimental, concurrent control and historical control groups

\begin{tabular}{|c|c|c|c|c|c|c|c|}
\hline \multirow[t]{2}{*}{ Demographic variables } & \multirow[t]{2}{*}{ Classification } & \multicolumn{2}{|c|}{$\begin{array}{l}\text { Experimental } \\
(300)\end{array}$} & \multicolumn{2}{|c|}{$\begin{array}{l}\text { Concurrent } \\
\text { Control }(300)\end{array}$} & \multicolumn{2}{|c|}{$\begin{array}{c}\text { Historical } \\
\text { Control (300) }\end{array}$} \\
\hline & & (f) & $(\%)$ & (f) & $(\%)$ & (f) & $(\%)$ \\
\hline \multirow{4}{*}{ Age } & Up to 30 years & 66 & 22.0 & 65 & 21.7 & 53 & 17.7 \\
\hline & $31-40$ years & 124 & 41.3 & 128 & 42.7 & 103 & 34.3 \\
\hline & $41-50$ years & 95 & 31.7 & 100 & 33.3 & 129 & 43.0 \\
\hline & Above 50 years & 15 & 5.0 & 7 & 2.3 & 15 & 5.0 \\
\hline \multirow[b]{2}{*}{ Gender } & Male & 168 & 56.0 & 161 & 53.7 & 168 & 56.0 \\
\hline & Female & 132 & 44.0 & 139 & 46.3 & 132 & 44.0 \\
\hline \multirow[b]{2}{*}{ Marital status } & Single & 29 & 9.7 & 44 & 14.7 & 10 & 3.3 \\
\hline & Married & 271 & 90.3 & 256 & 85.3 & 290 & 96.7 \\
\hline \multirow[b]{2}{*}{ Types of family } & Nuclear & 240 & 80.0 & 244 & 81.3 & 239 & 79.7 \\
\hline & Joint & 60 & 20.0 & 56 & 18.7 & 61 & 20.3 \\
\hline \multirow{3}{*}{ Types of caregivers } & Parents & 32 & 10.7 & 30 & 10.0 & 25 & 8.3 \\
\hline & Relatives & 246 & 82.0 & 226 & 75.3 & 253 & 84.3 \\
\hline & Friends & 22 & 7.3 & 44 & 14.7 & 22 & 7.3 \\
\hline \multirow{3}{*}{ Education } & Up to SSLC & 223 & 74.3 & 208 & 69.3 & 233 & 77.7 \\
\hline & Under Graduate & 48 & 16.0 & 52 & 17.3 & 50 & 16.7 \\
\hline & Graduate & 29 & 9.7 & 40 & 13.3 & 17 & 5.7 \\
\hline \multirow{4}{*}{ Occupation } & Self-employee & 233 & 77.7 & 216 & 71.3 & 251 & 83.6 \\
\hline & Professional & 40 & 13.3 & 47 & 15.7 & 30 & 10.0 \\
\hline & Business & 19 & 6.3 & 24 & 8.0 & 18 & 6.0 \\
\hline & Student & 8 & 2.7 & 13 & 4.3 & 1 & 0.3 \\
\hline \multirow[t]{2}{*}{ Previous hospitalization } & Yes & 142 & 47.3 & 157 & 52.3 & 150 & 50.0 \\
\hline & No & 158 & 52.7 & 143 & 47.7 & 150 & 50.0 \\
\hline \multirow[b]{2}{*}{ Department } & Medicine & 206 & 68.7 & 206 & 68.7 & 220 & 73.3 \\
\hline & Surgery & 94 & 31.3 & 94 & 31.3 & 80 & 26.7 \\
\hline
\end{tabular}


According to the table 1, more of the sample in experimental and concurrent control groups belonged to the age group of $31-40$ years $(41.3 \% \& 42.7 \%)$. In both the groups, more were male $(56.0 \% \& 53.7 \%)$. Majority were married $(90.3 \%$ \& $85.3 \%)$, from nuclear families $(80.0 \%$ \& $81.3 \%)$, had been staying in the hospital with the concerned patient $(82.0 \%$ \& $75.3 \%)$, had the basic level of SSLC, $(74.3 \% \& 69.3 \%)$, were self-employed $(77.7 \%$ \& $71.3 \%)$. In experimental group $52.7 \%$ had no previous hospital admission, whereas, $52.3 \%$ in the control group did have it. A good number $(68.7 \%)$ in both groups were with medical pathology. The historical control showed $43.0 \%$ was 41 to 50 years, $56.0 \%$ were male. $96.7 \%$ were married, $79.7 \%$ ) hailed from nuclear families, With regard to the level of education, $77.7 \%$ had passed SSLC; $83.6 \%$ were self-employed, $50 \%$ had the previous hospitalization. About $73.7 \%$ had sought admission with medical pathology.

\section{Table 2: Comparison of satisfaction with nursing care between experimental and concurrent control groups}

\begin{tabular}{|c|c|c|c|c|c|c|c|}
\hline & & & & & & \multicolumn{2}{|c|}{$\mathbf{N}=600(300+300$} \\
\hline Domains & Group & Mean & SD & MID & t value & df & p-value \\
\hline \multirow{2}{*}{$\begin{array}{l}\text { Information } \\
\& \text { Instructions }\end{array}$} & Exp & 25.12 & 2.593 & \multirow{2}{*}{8.027} & \multirow{2}{*}{$35.23 *$} & \multirow{2}{*}{598} & \multirow{2}{*}{$<0.001$} \\
\hline & Control & 17.09 & 2.975 & & & & \\
\hline \multirow{2}{*}{$\begin{array}{c}\text { Caring } \\
\text { behavior }\end{array}$} & Exp & 42.43 & 3.735 & \multirow{2}{*}{13.00} & \multirow{2}{*}{$34.94 *$} & \multirow{2}{*}{598} & \multirow{2}{*}{$<0.001$} \\
\hline & Control & 29.43 & 5.249 & & & & \\
\hline \multirow{2}{*}{$\begin{array}{c}\text { Restful } \\
\text { environment }\end{array}$} & Exp & 12.69 & 1.361 & \multirow{2}{*}{3.753} & \multirow{2}{*}{$28.44 *$} & \multirow{2}{*}{598} & \multirow{2}{*}{$<0.001$} \\
\hline & Control & 8.940 & 1.837 & & & & \\
\hline \multirow{2}{*}{$\begin{array}{c}\text { Discharge } \\
\text { process }\end{array}$} & Exp & 12.67 & 1.390 & \multirow{2}{*}{3.710} & \multirow{2}{*}{$26.79 *$} & \multirow{2}{*}{598} & \multirow{2}{*}{$<0.001$} \\
\hline & Control & 8.963 & 1.955 & & & & \\
\hline \multirow{2}{*}{$\begin{array}{c}\text { Quality of } \\
\text { service }\end{array}$} & Exp & 8.477 & 0.955 & \multirow{2}{*}{2.500} & \multirow{2}{*}{$25.39 *$} & \multirow{2}{*}{598} & \multirow{2}{*}{$<0.001$} \\
\hline & Control & 5.977 & 1.413 & & & & \\
\hline \multirow{2}{*}{$\begin{array}{c}\text { Recommend } \\
\text { services }\end{array}$} & Exp & 4.357 & 0.598 & \multirow{2}{*}{1.343} & \multirow{2}{*}{$25.82 *$} & \multirow{2}{*}{598} & \multirow{2}{*}{$<0.001$} \\
\hline & Control & 3.013 & 0.674 & & & & \\
\hline \multirow{2}{*}{$\begin{array}{c}\text { Overall } \\
\text { satisfaction }\end{array}$} & Exp & 105.74 & 8.403 & \multirow{2}{*}{32.33} & \multirow{2}{*}{$37.03 *$} & \multirow{2}{*}{598} & \multirow{2}{*}{$<0.001$} \\
\hline & Control & 73.41 & 12.57 & & & & \\
\hline
\end{tabular}

According to table 2, the independent sample t-test reveals that the mean of the post-test score is significantly high in the experimental group than in the concurrent control group at 0.05 level of significance $(p<0.001)$. Since the corresponding $\mathrm{p}$-value of the overall and the domain wise nursing care is less than the 0.05 level of significance $(\mathrm{p}<0.001)$, the difference between the two groups is statistically significant.

Table 3: Comparison of satisfaction with nursing care between the experimental group and its historical control

\begin{tabular}{|c|c|c|c|c|c|c|c|}
\hline Domains & Group & Mean & $\mathrm{SD}$ & $\mathrm{MD}$ & $\mathrm{t}$ - value & $\mathrm{df}$ & $\mathrm{p}$-value \\
\hline \multirow{2}{*}{$\begin{array}{l}\text { Information \& } \\
\text { Instructions }\end{array}$} & Exp & 25.12 & 3.279 & \multirow{2}{*}{6.573} & \multirow{2}{*}{$27.23 *$} & \multirow{2}{*}{598} & \multirow{2}{*}{$<0.001$} \\
\hline & H.Control & 18.54 & 2.593 & & & & \\
\hline \multirow{2}{*}{$\begin{array}{c}\text { Caring } \\
\text { behaviour }\end{array}$} & Exp & 42.43 & 4.628 & \multirow{2}{*}{11.46} & \multirow{2}{*}{$33.37^{*}$} & \multirow{2}{*}{598} & \multirow{2}{*}{$<0.001$} \\
\hline & H.Control & 30.97 & 3.735 & & & & \\
\hline \multirow{2}{*}{$\begin{array}{c}\text { Restful } \\
\text { environment }\end{array}$} & Exp & 12.69 & 1.581 & \multirow{2}{*}{3.590} & \multirow{2}{*}{$29.80 *$} & \multirow{2}{*}{598} & \multirow{2}{*}{$<0.001$} \\
\hline & H.Control & 9.103 & 1.361 & & & & \\
\hline \multirow{2}{*}{$\begin{array}{c}\text { Discharge } \\
\text { process }\end{array}$} & Exp & 12.67 & 1.445 & \multirow{2}{*}{3.593} & \multirow{2}{*}{$31.04 *$} & \multirow{2}{*}{598} & \multirow{2}{*}{$<0.001$} \\
\hline & H.Control & 9.080 & 1.390 & & & & \\
\hline \multirow{2}{*}{ Quality of service } & Exp & 8.477 & 2.572 & \multirow{2}{*}{2.183} & \multirow{2}{*}{$13.78^{*}$} & \multirow{2}{*}{598} & \multirow{2}{*}{$<0.001$} \\
\hline & H.Control & 6.293 & 0.955 & & & & \\
\hline \multirow{2}{*}{$\begin{array}{l}\text { Recommends } \\
\text { services }\end{array}$} & Exp & 4.357 & 0.549 & \multirow{2}{*}{1.350} & \multirow{2}{*}{$28.82 *$} & \multirow{2}{*}{598} & \multirow{2}{*}{$<0.001$} \\
\hline & H.Control & 3.007 & 0.598 & & & & \\
\hline \multirow{2}{*}{$\begin{array}{c}\text { Overall } \\
\text { satisfaction }\end{array}$} & Exp & 105.7 & 11.32 & \multirow{2}{*}{28.75} & \multirow{2}{*}{$35.33^{*}$} & \multirow{2}{*}{598} & \multirow{2}{*}{$<0.001$} \\
\hline & H.Control & 77.00 & 8.403 & & & & \\
\hline
\end{tabular}


Table 3 reveals the results of the independent sample t-test that analyzed the difference in the mean scores of satisfaction with nursing care among the experimental group and its historical control. The sample for the data collection came from the interventional wards in two periods: the first, six weeks before the actual intervention and the second, during the intervention. The corresponding $\mathrm{p}$-value of overall satisfaction and the satisfaction with each of the domains of nursing care is less than the 0.05 level of significance. Since the obtained level of significance is less than 0.05 level $(\mathrm{p}<0.001)$, the difference between the two groups in their satisfaction with nursing care is considered to be statistically significant. The mean score is significantly high in the sample exposed to SNCR, when compared to the sample exposed to the routine care.

Table 4: Association between satisfaction with nursing care and selected patient demographic variables

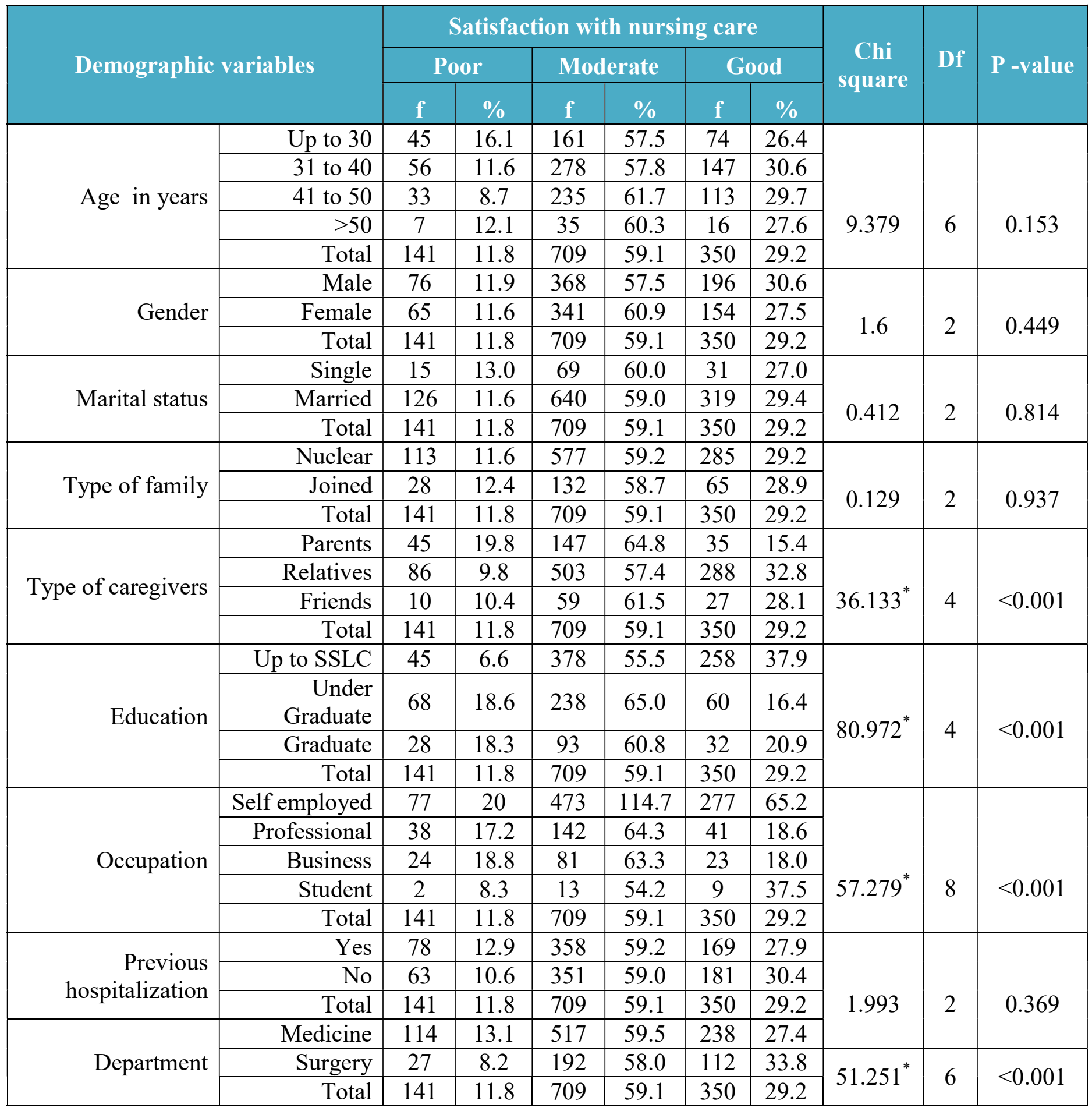

The statistical analysis revealed no association between patient satisfaction with nursing care and their selected demographic variables: age $(p=0.153)$, gender $(p=0.449)$, marital status $(p=0.814)$, type of family, $(p=0.937)$, 
education $(p<0.001)$ and previous hospitalization $(p=0.369)$. The obtained chi-square values were not statistically significant at 0.05 level. However, certain association was observed between patient satisfaction with nursing care and occupation of patients $(p<0.001)$, type of caregivers $(p<0.001)$, and the department of admission $(\mathrm{p}<0.001)$. The statistical association between patient satisfaction with nursing care and these demographic variables of the patient sample was significant at 0.05 level.

\section{Results:}

\section{Patient satisfaction with nursing care:}

The mean of the post-test score is significantly high in the experimental group than in the concurrent control group at 0.05 level of significance $(\mathrm{p}<0.001)$.

\section{Association between satisfaction with nursing are and selected patient variables:}

A significant association was found between satisfaction with nursing care and relatives with the patient $\left(\chi^{2}=36.133, \mathrm{p}<0.001\right)$, education $\left(\chi^{2}=80.972\right.$, $\mathrm{p}<0.001)$, occupation $\left(\chi^{2}=57.279, \mathrm{p}<0.001\right)$ and department $\left(\chi^{2}=51.251, \mathrm{p}<0.001\right)$.

\section{Interpretation:}

In sum, therefore, the findings suggested that structured nursing care rounds performed at set intervals by nursing personnel were associated with statistically significant increase in the patient satisfaction with nursing care.

\section{Discussion}

An analysis of the mean score for the domains of satisfaction with nursing care, in the experimental group, a significant rise was found in the different areas of care: information and instruction $(p<0.001)$, caring behaviour $(\mathrm{p}<0.001)$, restful environment $(\mathrm{p}<0.001)$, discharge instructions and procedures $(p<0.001)$, quality of nursing and hospital services $(p<0.001)$, and recommendation of services to others $(\mathrm{p}<0.001)$.

At the experimental level, the analysis confirmed that SNCR practiced by the nursing personnel effected an increase in patient satisfaction with nursing care. Therefore, the relationship between patient satisfaction and SNCR has been established through statistical scores, which strongly supported the research hypothesis $\left(\mathrm{H}_{1.1}\right)$. Therefore, the null hypothesis $\left(\mathrm{H}_{01.1}\right)$ was rejected.

The SNCR, the independent variable under study, has strong and justifiable evidence base from previous studies. This is evident from the measures of improved patient satisfaction, obtained from a larger proportion of such studies that measured patient satisfaction as an evaluated item of the effectiveness of hourly rounds. ${ }^{86}$

The study by Meade et al. (2006) serves as a motivation for the 'go in line with' of the present research. They had done a six-week nationwide research which revealed a statistically significant increase in patient satisfaction scores $(12 \%, \mathrm{p}=0.001)$. The mean score for the period prior to the one-hour round units was 79.9 on a 100-point scale, while the mean score on those units, during the rounds was 91.9 $(t=736.58, p=0.001)$. Prior to the nursing rounds, the mean score for two-hour rounding units was 70.4, and during the protocol, the mean score was 82.1 $(t=657.11, p=0.001)$. Thus, both the groups were seen to have significant increase in patient satisfaction scores. $^{15}$

\section{Advantages of using historical and concurrent controls in the present study}

The concurrent groups are the active groups. Active/concurrent control is usual/routine rounds, which is normally provided to patients with a given condition. The concurrent control group received the routine/standard intervention while a treatment/intervention group received the experimental intervention (SNCR). There are many advantages in comparing the experimental group with historical and concurrent controls. The use of historical control addresses some of the factors that might jeopardize the internal validity of an experiment/intervention.

The comparison of experimental group with historical and concurrent controls helped towards the internal validity of the experimental nursing intervention, specifically giving sufficient evidence that the difference in patient satisfaction with nursing care is due to the new intervention (SNCR). At this time, the researcher ensured that no specific events (history) occurred in the intervention and comparisons wards between the first and second measurement of patient satisfaction with nursing care. The data was collected on the day of discharge and no pretesting and that 
addressed maturation processes within sample which act as a function of the passage of time. The pre-test on the satisfaction with nursing care was not feasible as the patient was rightly introduced into the new intervention on admission itself (testing). There were no changes in the instrument, observers, or scorers which may produce changes in outcomes (instrumentation).

The patient satisfaction with nursing care was not extremely poor in wards to show immediate improvement right after the intervention (statistical regression). The comparison wards were selected randomly; also the all the eligible patients were included in the sampling frame to avoid bias (selection of bias). To address John Henry effect, the sample (staff nurses) in the experimental group outperform under the presence of the researcher and awareness that their performance is being observed, after introducing the new intervention, the researcher withheld for another eight weeks before the second measurement on patient satisfaction with nursing care.

To address reactive arrangements that refer to the artificiality of the experimental setting and subject's knowledge that he/she is participating in an experiment, the intervention was introduced into the natural setting of each selected wards. To remediate this problem, SNCR was incorporated as variants of the regular practice, measurements were integrated into the normal testing routine, and SNCR was delivered by regular staff. The SNCR implementation originated with nursing personnel.

\section{Conclusion}

In the clinical study on effect of structured nursing rounds on patient satisfaction with nursing care, historical control (patients admitted in the past) and their perception on satisfaction with nursing care was used in post test only design (had no pre-test) to study the effect of a new clinical nursing intervention. In non-equivalent control group post-test only design, use of a historical control and concurrent controls helped the researcher determine the effects of a new treatment more accurately. Internal validity exists when the results of an experiment can be confidently attributed to the effect of the independent variable. The addition of the historical measurement allowed researcher to address the problem of assignment bias that exists with all non-equivalent group research. With the addition of a historical control to the nonequivalent post-test only control group design reduced some threats to internal validity, although it did not eliminate them completely.

\section{References}

1. Baker, S. \& Lindeman, K. (2001). Rethinking H.C. Biostatistics. 2, 4. pp. 383-396. Viele, K. et. al. (2014). Use of H.C. data for assessing treatment effects in clinical trials. Pharm Stat. 2014 Jan-Feb; 13(1): 41-54.

2. Bennett et al. (2015). Incorporating historical control data into the design and analysis of clinical trials. $3^{\text {rd }}$ International Clinical Trials Methodology Conference. Trials 2015 (Suppl 2):P205

3. Edmund A. Gehan. The evaluation of therapies: Historical control studies. Statistics in Medicine. Vol-3, 315-324 (1984).

4. Glasziou P, Chalmers I, Rawlins M, McCulloch P (2007). When are randomized trials unnecessary? Picking signal from noise. BMJ 334:349-351.

5. Google search, available at:http://www.jameslindllibrary.org.

6. Jigar R Desai et. Al (2013). Creation and implementation of a historical controls database from randomized clinical trials. J Am Med Inform Assoc. 2013 June; 20 (e1): e 162 -e 168.

7. Loudon I (2002). The use of historical controls and concurrent controls to assess the effects of sulphonamides, 1936-1945. JLL Bulletin: Commentaries on the history of treatment evaluation.

8. Marc K Walton $\mathrm{MD}, \mathrm{PhD}$. Historical Controls for Clinical Trials Contemplation on Use in Drug Development. FDA Small Clinical Trials Course White Oak December 2012. Google search, available at: https://events-support.com.

9. Meade, Brusel \& Ketelsen.Effects of nursing rounds: on patients' call light use, satisfaction and safety. American Journal of Nursing. 2006; 106 (9):58-70.

10. Paul C. Price et al. Non-Equivalent Groups Designs. Google Search, available at: https://p[emtext.wsu.edu.

11. Phyllis Supino (2014). Fundamental issues in evaluating the impact of interventions sources and control of bias. Google search, available at https://www.reserch gate.net/publication/278693697. 
12. Pocock, S.J (1976). The combination of randomized and historical controls in clinical trials. Journal of Chronic Diseases 1976 Vol.29 No.3 pp.175-188.

13. Reimer N, Herbener. Round and round we go: Rounding strategies to impact exemplary professional practice: Clinical Journal of Oncology Nursing. 2014 ;18(6): 654-60

14. Schnall, S., Benton, J., \& Harvey, S. (2008). With a clean conscience: Cleanliness reduces the severity of moral judgments. Psychological Science, 19(12), 1219-1222. doi: 10.1111/j.14679280.2008.02227.x

15. Schnall, S., Haidt, J., Clore, G. L., \& Jordan, A. H. (2008). Disgust as embodied moral judgment. Personality and Social Psychology Bulletin, 34, 1096-1109.

16. Segen's Medical Dictionary (2011). Historical control. Avaialable at:htt[s://medical dictionary. The freedictionary.com

17. Treng HM, Ketefian $\mathrm{S}$ \& Redman RW. Relationship of nurses' assessment of organizational culture, job satisfaction, and patient satisfaction with nursing care: International Journal of Nursing Studies. 2002; 39:79-84.

18. Ulanimo V, Ligotti N. Patient satisfaction and patient safety: Outcomes of purposeful rounding TIPS: VA National centre for patient safety. 2011;11(4): 2 